\title{
Increasing the Thermostability of Optoelectronic Devices on Semiconductor Radiators
}

\author{
DalievKhojiakbarSultanovich $^{\mathrm{a}}$, NasriddinovSayfulloSayidovich ${ }^{\mathrm{b}}$, KuldashovObbozzhonKhokimovich ${ }^{\mathrm{c}}$, \\ AbdurakhmonovSultonaliMukaramovich ${ }^{\mathrm{d}}$, Mirzazhanov Mahmud Akhmedovich ${ }^{\mathrm{e}}$, \\ KhaidarovAbbosAnvarovich ${ }^{\mathrm{f}}$ \\ ${ }^{a}$ Branch of the National Research University MPEI, Director \\ ${ }^{\mathbf{b}}$ Research Institute "Physics of Semiconductors and Microelectronics National University of Uzbekistan, Deputy Director \\ chead of the department, ${ }^{\mathrm{d}, \mathrm{e}, \mathrm{f}}$ Associate Professor, \\ c,d,e,f Fergana branch of Tashkent University of Information Technologies
}

Article History: Received: 10 November 2020; Revised 12 January 2021 Accepted: 27 January 2021; Published online: 5 April 2021

\begin{abstract}
The article proposes a scheme for thermal stabilization of the radiation flux of mid-IR LEDs in the temperature range $+20^{\circ} \mathrm{C}+80^{\circ} \mathrm{C}$.

It is shown that the relevance of mid-IR LEDs for solving problems of gas analysis, environmental monitoring, moisture measurement and medical diagnostics.

It was revealed that the guarantee of the measurement accuracy and sensitivity of optoelectronic devices is the correct spectral matching of the photodetector, LED and absorption of the investigated substance.

The disadvantages of emitting diodes associated with time and temperature instability during operation are considered.

A study of the spectral characteristics of mid-IR LEDs at various temperatures showed that the wavelength at the maximum the emission spectrum increases almost linearly with increasing temperature, which leads to additional errors and lowers the measurement accuracy of optoelectronic devices.
\end{abstract}

A schematic diagram is proposed for stabilizing the radiation flux of mid-IR LEDs in the temperature range $+20^{\circ} \mathrm{C}+80^{\circ} \mathrm{C}$. Keywords: optoelectronics, absorption, LEDs, photodetectors, IR range, temperature, stability, thermal stabilization, devices

\section{Introduction}

Technological advances in the development and manufacture of mid-IR LEDs are widely used in various industries. Mid-IR - the region is especially relevant when solving problems in the field of gas analysis, monitoring of the ecological situation of the environment, moisture measurement, medical diagnostics and communication systems is important primarily for environmental protection, since absorption bands of the main natural and industrial gases lie in this range ( $\mathrm{H} 2 \mathrm{O}, \mathrm{CO} 2, \mathrm{CO}, \mathrm{CH} 4, \mathrm{NO} 2, \mathrm{H} 2 \mathrm{~S}$, etc.), as well as combustible and explosive substances. Optoelectronic sensors are in demand in medicine for monitoring the exhaled mixture, anesthetics, diagnosing blood glucose, etc.

The main areas of application of IR sensors.

\section{Ecology:}

- measuring the concentration of carbon dioxide in the premises;

- measuring the concentration of carbon dioxide on city streets;

- control of exhaust gases of cars;

- control of biogas composition at landfills;

- control of leaks of domestic natural gas;

- control of emissions of harmful gases into the atmosphere;

- control of water pollution by hydrocarbons.

\section{Medical diagnostics:}

- measurement of carbon dioxide in exhaled air;

- measurement of acetone in exhaled air;

- non-invasive analysis of blood glucose.

\section{Oil, gas and coal industry:}

- $\quad$ measurement of water content in oil; 
- measurement of hydrogen sulfide content in oil;

- control of methane leaks.

\section{Chemical industry:}

- continuous monitoring of technological processes.

\section{Pulp and paper industry:}

- continuous control of paper moisture during production.

\section{Food industry and agriculture:}

- measurement of moisture content of grain and other products;

- measuring the content of gluten and other substances in grain.

\section{Literature review}

It is known that, based on studies of GaInAsSb / GaAlAsSb, InAs / InAsSbP, InAs / InAlAsSb, highperformance LEDs for the mid-IR spectral regions of 1.6-2.4 and 3.0-4.8 $\mu \mathrm{m}$ have been created [1-3], longwavelength broadband photodiodes based on InAsSbP / InAs compounds have been developed. operating at room temperature $[4,5]$.

At present, a whole class of optoelectronic sensors has been developed: an analyzer of water content in oil [6], carbon dioxide and methane [7], moisture content of materials [8, 9].

To solve typical applications, it becomes necessary to ensure stable operation of LEDs. One of the disadvantages of emitting diodes is their temporal and temperature instability.

Stabilization of the parameters of emitting diodes can be done in the following ways:

- introduction of heat-sensitive elements into the power supply circuit [10];

- the choice of resistances in the power supply circuit [11];

- introduction of feedback on the temperature-sensitive parameter [12];

- stabilization by introducing an optical comparison channel [13, 14].

The considered methods make it possible to reduce the radiation instability. However, they also have relatively limited capabilities and it becomes necessary to take additional measures to mitigate instability.

As you know, the spectral distribution of the radiation power and the maximum of the emission spectrum of LEDs depend on temperature [16].

A decrease in the band gap with an increase in temperature leads to a shift of radiation towards a longer wavelength [17].

One of the main characteristics of LEDs is radiation flux and optical power. They are not exactly described in the technical data sheets of the device and depend on both the excitation current and the junction temperature [18]. To ensure high reliability and efficiency of application of mid-IR LEDs, the necessary operating conditions are created [19]. The optical and electrical characteristics of an LED are highly dependent on the junction temperature, which in turn depends on

from a heat source including current and temperature [20-22].

LEDs need to maintain more accurate specifications in order to be used in non-destructive testing devices. Stabilizing current and temperature is important to achieve consistent spectral properties and optimize mid-IR LEDs.

\section{Research methods}

The measurements were carried out using a spectrometer for recording the optical parameters and spectrum of the LED under various operating conditions. In this work, we use GaInAsSb / GaAlAsSb LEDs with emission spectra of $1.6-2.4 \mu \mathrm{m}$. 
Table 1.

\begin{tabular}{|c|c|c|c|c|c|}
\hline Parameter name & $\begin{array}{c}\text { Designat } \\
\text { ion }\end{array}$ & $\begin{array}{c}\text { Operating } \\
\text { condition, at } \\
+70^{\circ} \mathrm{C}\end{array}$ & $\begin{array}{c}\text { Minimum } \\
\text { value }\end{array}$ & $\begin{array}{c}\text { Maximum } \\
\text { value }\end{array}$ & $\begin{array}{c}\text { unit of } \\
\text { measurement }\end{array}$ \\
\hline $\begin{array}{c}\text { Wavelength at the } \\
\text { maximum of the } \\
\text { spectrum }\end{array}$ & $\lambda_{\mathrm{p}}$ & $\mathrm{I}_{\mathrm{F}}=150 \mathrm{~mA}$ & \multicolumn{2}{|c|}{$\lambda_{m}=1.95$} & $\mathrm{mkm}$ \\
\cline { 1 - 5 } Spectrumhalf-width & $\Delta \lambda$ & $\mathrm{I}_{\mathrm{F}}=150 \mathrm{~mA}$ & 100 & 200 & $\mathrm{~nm}$ \\
\hline Pulsedopticalpower & $\mathrm{P}^{*}$ QCW & $\mathrm{I}_{\mathrm{F}}=200 \mathrm{~mA}$ & 0.8 & 1.92 & \multirow{2}{*}{} \\
\cline { 2 - 5 } & $\mathrm{P}^{* * *}$ Pulsed & $\mathrm{I}_{\mathrm{F}}=100 \mathrm{~mA}$ & 4.4 & 6.6 & \\
\hline Forwardvoltage & $\mathrm{V}_{\mathrm{F}}$ & $\mathrm{I}_{\mathrm{F}}=200 \mathrm{~mA}$ & 0.5 & 1.5 & $\mathrm{~B}$ \\
\hline speed & $\tau$ & $\mathrm{I}_{\mathrm{F}}=200 \mathrm{~mA}$ & 10 & 30 & $\mathrm{~ns}$ \\
\hline
\end{tabular}

The characteristics of the LEDs used in this work are shown in Table 1. It can withstand maximum forward current and ambient temperatures up to $150 \mathrm{~mA}$ and $70^{\circ} \mathrm{C}$, respectively.

To measure the electrical and optical characteristics of LEDs in the temperature range of 77-400 K, a thermostat was created, the design of which is shown in Fig. 1.

The thermostat allows you to set any temperature of the sample in the temperature range $77-400 \mathrm{~K}$ and maintain it with an accuracy of $0.5 \mathrm{~K}$ throughout the entire measurement cycle.

The main parts of the thermostat: a heat chamber 2 and a container for liquid nitrogen 3, connected by channel I and thermally insulated with a vacuum gap 4 . The whole structure is like a double Dewar vessel. The heat chamber is hermetically closed with a glass stopper with a ground-in section. On the carpet, two 10 plugs are fixed: a holder 11 , an electric heater 5 , a heat conductor 6 , a diode holder 7 , a refrigerant conduit 8 . Wires for the LED, heater and thermocouples pass through the plug.

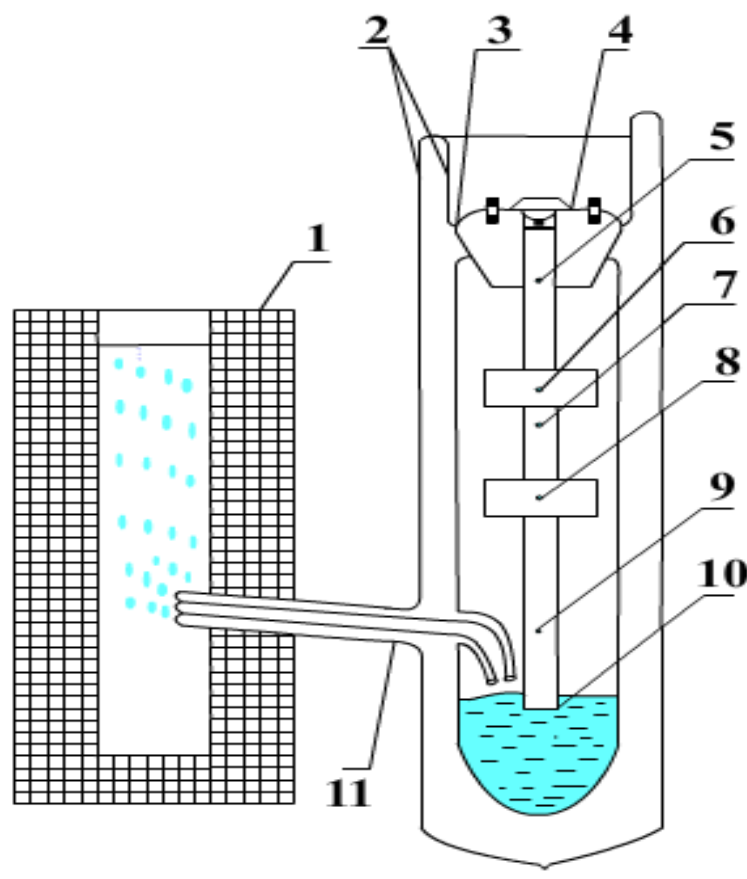

Figure: 1. Thermostat for electroluminescent measurements in the temperature range $77-400 \mathrm{~K}$

The principle of operation of the thermostat is based on the self-maintenance of the liquid nitrogen level at a fixed height. The height of the level is fixed by the position of the inlet 9 of channel 1 . Through the channel, firstly, nitrogen vapor from the heat chamber is vented, and secondly, the liquid flows instead of the evaporated 
one. As a result, the liquid level in the heat chamber is fixed at the height of hole 9, regardless of the level of liquid nitrogen in the container.

As needed, nitrogen is added to the container, while the operating mode of the thermostat is not disturbed. The temperature in the thermostat will be constant if the current through the electric heater is stabilized.

Figure 2 shows a block diagram of the installation, which allows you to implement the proposed method. A direct current from the power supply unit 3 is passed through the LED-1 placed in the cryostat- 2 in the forward direction. The voltage drop across the structure is set in the range from 0 to $1 \mathrm{~V}$ and is measured with a voltmeter 5. Using a logarithmic amplifier-6 we obtain the logarithm of the current $\lg I$.

To measure the temperature, we used a device based on a temperature sensor made on the basis of silicon doped with nickel [23].

Since the measuring device has increased requirements for the measurement accuracy, it is necessary to equip the device with an automatic self-calibration and self-diagnosis system, which will fundamentally distinguish (for the better) the device under development from analogs based on once set accurate input stages of conditioning the measured signal. The introduction of an automatic auto-calibration system into the measuring device with its own basic (technical class) reference standards will significantly increase the accuracy characteristics of the device, both in short-term and long-term time intervals commensurate with the service life.

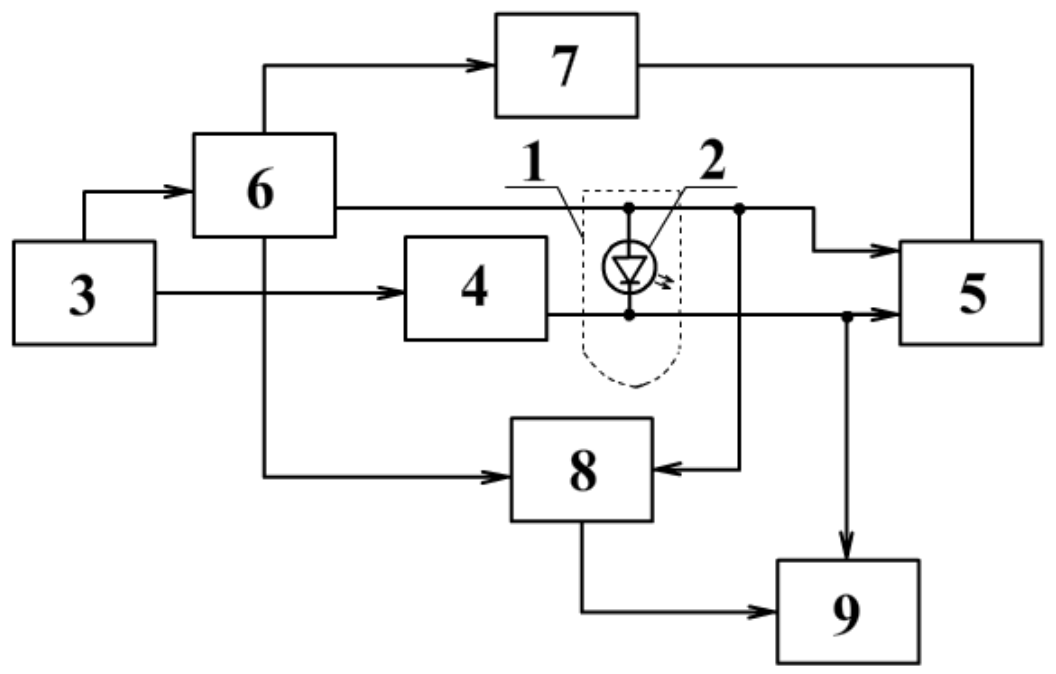

Figure: 2. Block diagram of the experimental setup

The LED temperature was measured by a thermosensitive element and by the shift of the emission band maximum.

Figure 3 shows the spectral characteristics of LEDs with a wavelength of $2.3 \mathrm{~mm}$ at different temperatures.

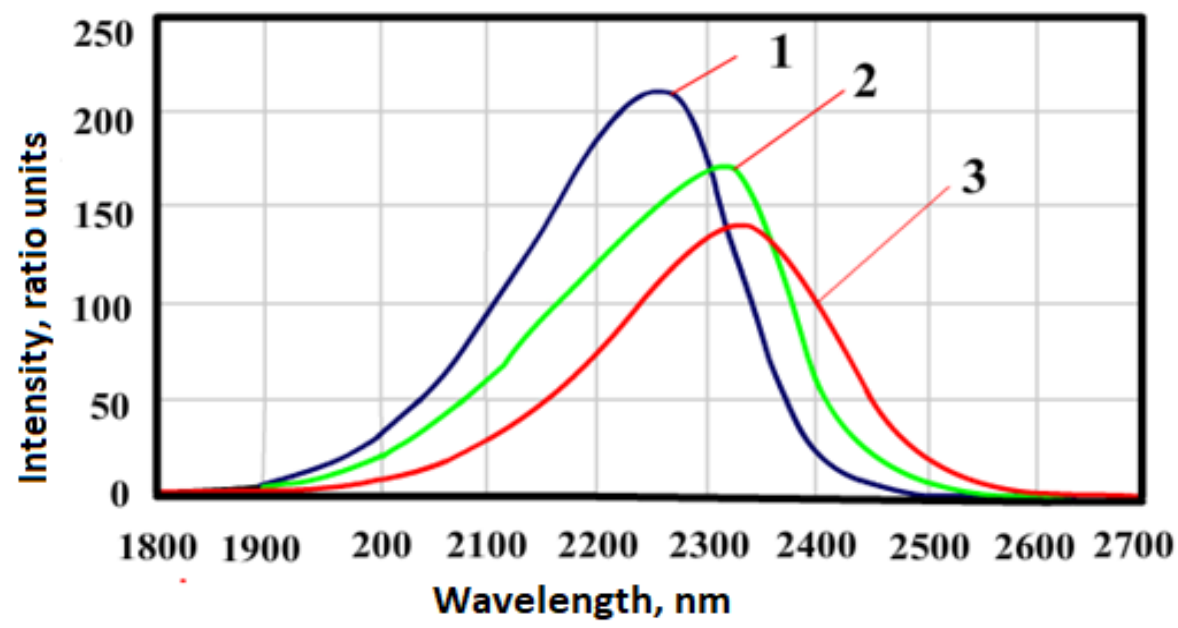

Fig. 3. Spectral characteristics of LEDs with a wavelength of $2.3 \mu \mathrm{m}$, where:1-50C, 2 - 240C, 3 - 500C 


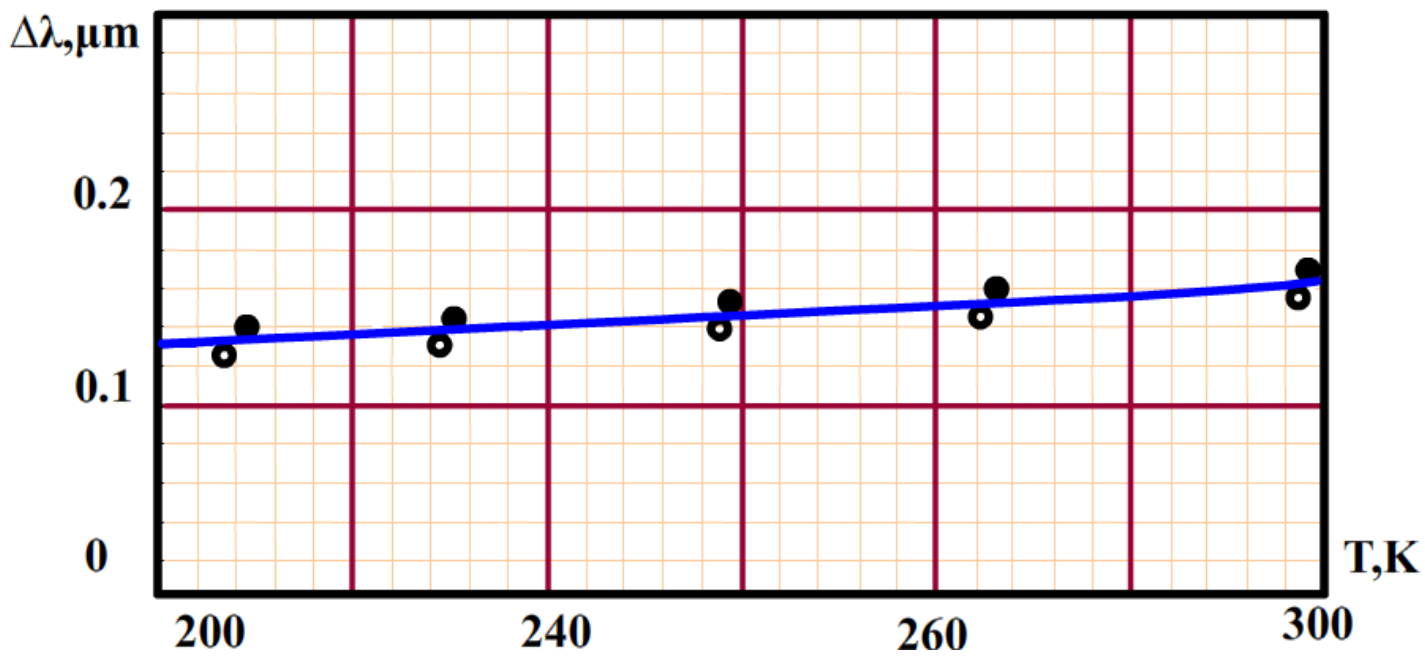

Figure: 4. Temperature dependence of the wavelength at half-width of the radiation spectrum

Analysis of the shape of the curves shows that the wavelength at the maximum

the emission spectrum increases almost linearly with increasing temperature according to the law:

$$
\frac{d \Delta \lambda}{d T}=\lambda^{2} \cdot 2,8 \cdot 10^{-4}, \frac{\mathrm{mkm}}{\mathrm{K}}
$$

In the temperature range $(300-320 \mathrm{~K})$, the wavelength at the maximum changes by $0.009-0.01 \mu \mathrm{m}$ (Fig. 4 ). And the half-width of the radiation spectrum - quadratically depends on the wavelength at the maximum at room temperature and the temperature dependence of the half-width of the spectrum is expressed by the formula:

$$
\frac{d \Delta \lambda}{d T}=\lambda^{2} \cdot 10^{-4}, \frac{\mathrm{mkm}}{\mathrm{\kappa}}
$$

During operation, LEDs are significantly affected by the ambient temperature. In real operating conditions, the ambient temperature can vary from $-30 \mathrm{oC}$ to $+60 \mathrm{oC}$.

\section{Results and discussion}

The basis for the construction of optoelectronic sensors is

the property of a substance to absorb IR - radiation of a certain wavelength, if the controlled object is irradiated with IR radiation with a wavelength lying in the absorption band of the substance, and the fraction of radiation after interaction with it is recorded, then the value of the controlled component can be judged. Therefore, the system for converting the monitored parameter into a photoelectric signal is based on the fact that the monitored

an object is irradiated with a flux of a certain spectral composition, a fraction of the radiation after interaction is taken and converted

into a photoelectric signal (photocurrent).

Spectral matching of the photodetector, LED and absorption of the investigated substance is a guarantee of measurement accuracy, sensitivity of optoelectronic automatic control devices.

In this regard, the main parameters of mid-IR LEDs were investigated at various temperatures.

The obtained data on the instability of the radiation flux of LEDs in the mid-IR region in the temperature range $+20^{\circ} \mathrm{C}+80^{\circ} \mathrm{C}$ with an operating time of 12,000 hours are presented in Table 2. 
Table 1

\begin{tabular}{|r|c|c|c|c|c|}
\hline SD type & $\begin{array}{c}\text { Wavelen } \\
\text { gth, } \mu \mathrm{m}\end{array}$ & $\begin{array}{c}\text { LED } \\
\text { current, } \\
\mathrm{mA}\end{array}$ & $\begin{array}{c}\text { Operatingti } \\
\mathrm{me}, \mathrm{h}\end{array}$ & $\begin{array}{c}\text { Temperature } \\
\text { Range }\end{array}$ & $\begin{array}{c}\Delta \mathrm{F}_{, \%} \\
\end{array}$ \\
\hline LED 19 & 1.94 & 50 & 12000 & $+20 \ldots+80$ & 6.50 \\
\hline LED 22 & 2.2 & 50 & 12000 & $+20 \ldots+80$ & 6.45 \\
\hline LED 34 & 3.39 & 50 & 12000 & $+20 \ldots+80$ & 6.82 \\
\hline LED 32 & 3.20 & 50 & 12000 & $+20 \ldots+80$ & 6.76 \\
\hline LED 15 & 1.55 & 50 & 12000 & $+20 \ldots+80$ & 6.59 \\
\hline
\end{tabular}

Experimental studies have shown that the parameters of mid-infrared LEDs are determined by the ambient temperature and their thermostable operation in the circuit depends on how well temperature compensation or thermostatingcan be provided. However, thermostating of optoelectronic devices is often difficult or impossible. In this case, the use of temperature compensation of electronic elements is effective.

A schematic diagram for stabilizing the radiation flux of mid-IR LEDs in the temperature range $+20^{\circ} \mathrm{C}+80$ ${ }^{\circ} \mathrm{C}$ is proposed (Fig. 5).

The principle of operation of this circuit is based on the stabilization of the forward voltage at the $p$-n junction of the LED. As you know, the change in the temperature of the voltage drop of the p-n junction. The study of this circuit showed that with the help of temperature stabilization of the voltage drop at the $p-n$ junction of the LED, it is possible to provide temperature stabilization of the LED, as a result of sufficient stability of the LED radiation flux.

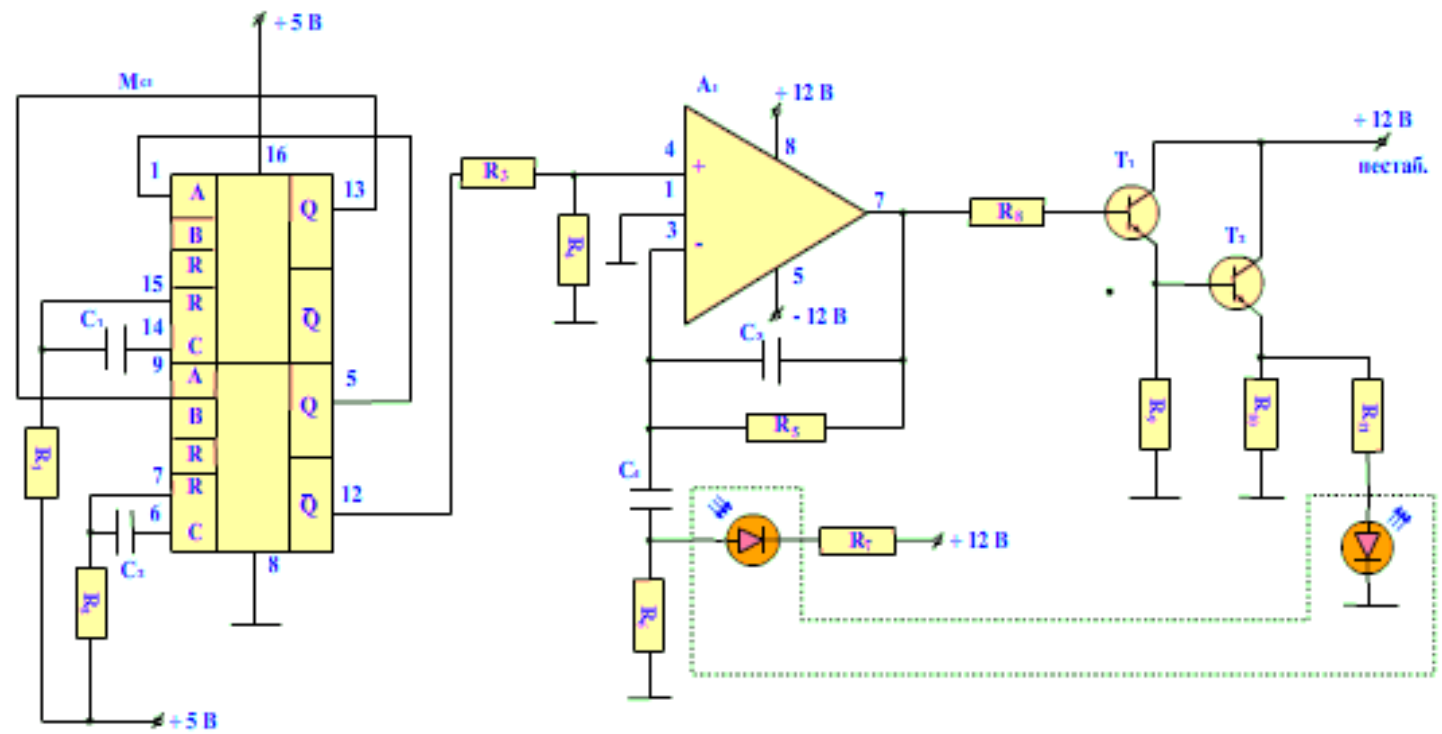

Fig. 5. Schematic diagram for stabilizing the radiation flux of LEDs

For this circuit, a special design of an optocoupler has been developed, which consists of an LED measuring wavelength and an additional photodiode on a standard TO-18 case (Fig. 3). 

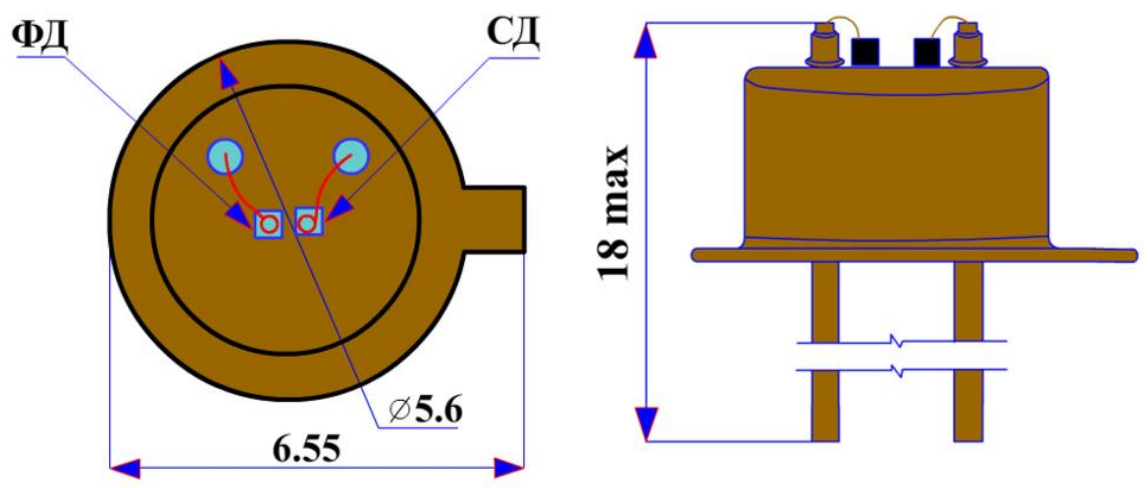

Fig. 6. Optocoupler design on a standard bodyTO -18 .

On its basis, it is possible to implement a circuit solution for temperature stabilization of the LED radiation flux, which provides a high stabilization coefficient in the temperature range of $+20^{\circ} \mathrm{C}+80^{\circ} \mathrm{C}$, due to the feedback on the radiation flux.

The results of experimental studies of a circuit solution for stabilizing the parameters of a mid-IR LED are shown infig 7.

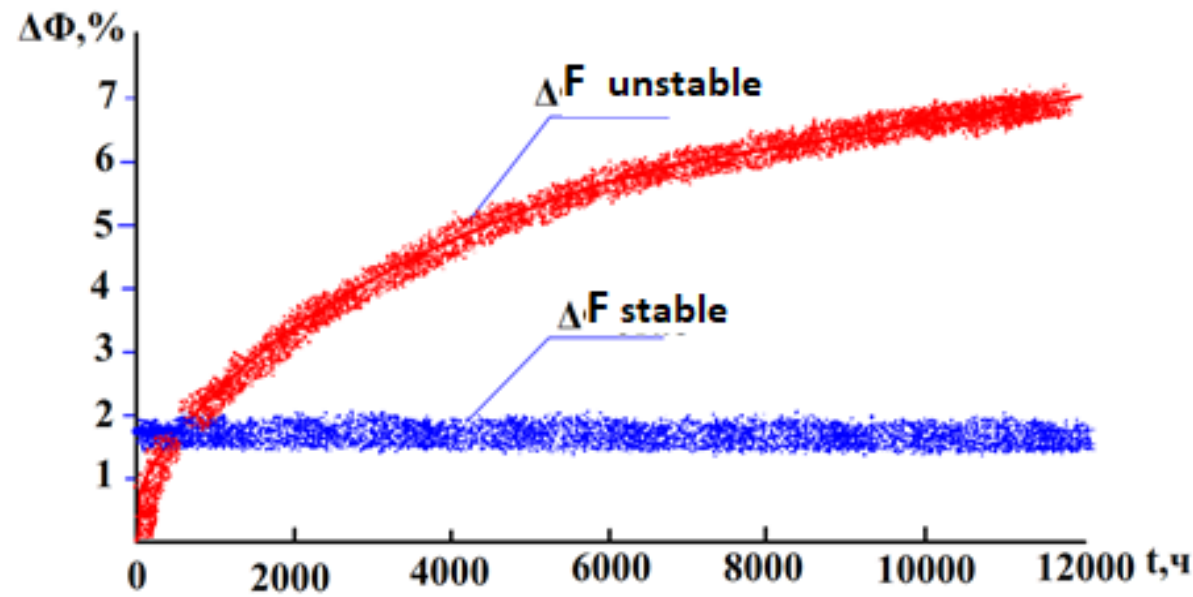

Fig. 7. The results of the stabilization of the parameters of the average LED

IR - areas

\section{Conclusion}

The use of the developed thermal stabilization scheme made it possible to reduce the instability of the radiation flux of mid-IR LEDs to 3 ... 5\% and ensured an increase in their service life.

For experimental studies, LEDs based on GaAlAsSb / GaInAsSb / GaAlAsSb of the Russian company AIBI were used, the lifetime of which was more than 150,000 hours of continuous operation.

A special design of an opto-coupler has been developed, consisting of an LED with a measuring wavelength and an additional photodiode on a standard TO-18 package; on its basis, a circuit solution for temperature stabilization of the radiation flux of mid-IR LEDs is implemented.

\section{References}

Alferov Zh.I. Double heterostructures: concept and applications in physics, electronics and technology // Uspekhi fizicheskikh nauk. - 2002. - S. 1068-1086. doi: 10.3367 / UFNr.0172.200209e.1068.

Mikhailova MP, Ivanov EV, Danilov LV, Kalinina KV, Yakovlev Yu. P., Kopyev PS Radiative recombination and impact ionization in semiconductor nanostructures (Review) // Technical Physics Journal. - 2020. - T.54. - S. 1267 - 1269.doi: 10.21883 / ftp.2020.12.50226.9509.

Romanov VV, Ivanov EV, Pivovarova AA, Moiseev KD, Yakovlev Yu. P. Long-wave LEDs in the atmospheric transparency window of 4.6-5.3 $\mu \mathrm{m} / /$ Journal of technical physics. - 2020. - B.2. - S. 202 - 205.

doi: 10.21883 / ftp.2020.02.48906.9278. 
Alotaibi M., Balabid M., Albeladi W., Alharbi F. Implementation of Liquid Level Control System. - 2019.doi: 10.1109 / I2CACIS.2019.8825058.

Danilov L.V., Petukhov A.A., Mikhailova M.P., Zegrya G.G., Ivanov E.V., Yakovlev Yu.P. Features of hightemperature electroluminescence in LED n-GaSb / n-InGaAsSb / p-AlGaAsSb heterostructure with high potential barriers // Journal of technical physics. - 2016. - T. 50. - S. 794 - 800.

Bogdanovich M.V. Kabanov D.M., Lebedok E.V., Shpak P.V., Ryabtsev A.G., Ryabtsev G.I., Schemelev M.A., Andreev I.A., Kunitsyna E.V., Ivanov E V.V., Yakovlev Yu.P. Meter of water content in oil and oil products based on infrared optoelectronic pairs LED-photodiode // Journal of technical physics. - 2017. Volume 87. Issue 2. - S. 315 - 318.doi: 10.21883 / jtf.2017.02.44146.1791.

Zagnitko A.V., Zaretsky N.P., Kanikevich A.V., Matsukov I.D., Fedin D.Yu. "Infrared gas analyzers of methane air streams // Instruments and experimental techniques. - 2019.doi: 10.1134 / s0032816219040359.

Ohno Y. Color quality of white LEDs // in Topics in Applied Physics. - 2017.P.457-480 DOI: 10.1007 / 978-98110-3755-9_16

Bender V. C., Marchesan T. B., Alonso J. M. Solid-State Lighting: A Concise Review of the State of the Art on LED and OLED Modeling // IEEE Industrial Electronics Magazine. 2015, doi: 10.1109 / MIE.2014.2360324.

Patent RU2034277 C1, 1995. Tsimberova I.S., Kovalev I.K., Panteleev Yu.K. Method for stabilizing the parameters of emitting diodes.

Wan H., Zhang D., Sun X. Stabilization of a superfluorescent fiber source with highperformance erbium doped fibers // Optical Fiber Technology. 2013. T. 1. No. 3. P.264-268.

Sharkov I.A., Rupasov A.V., Strigalev V.E., Volkovsky S.A. Influence

temperature instability of the source characteristics per indication

fiber optic gyroscope // Scientific and technical bulletin

information technology, mechanics and optics. 2013. No. 6. P. 31-35.

Patent RU2163412 C1, 2001. Gorbunkov, M.V. Yu.V. Shabalin Method for stabilizing laser radiation.

Zakharenko V.A., Shkaev A.G., Sayfutdinov R.N. Ensuring the stability of photodiode sensors // Methods and means of measurement in control and management systems: Proceedings of the Intern. scientific and technical conf. - Penza, 2002 .-- S. 10-12.

I. Ashdown and M. Salsbury, "Peak wavelength shifts and opponent color theory," in Optical Engineering + Applications, 2007, pp. 66690C-66690C-10.

G. S. Spagnolo, D. Papalillo, A. Martocchia, and G. Makary, "Application of LEDs to traffic signal," in Environment and Electrical Engineering (EEEIC), 2012

11th International Conference on, 2012, pp. 864-868.

A. Poppe, G. Molnár, and T. Temesvolgyi, "Temperature dependent thermal resistance in power LED assemblies and a way to cope with it," in Semiconductor Thermal Measurement and Management Symposium, 2010. SEMITHERM 2010. 26th Annual IEEE. 2010, pp. 283-288.

H. Chen and S. Hui, "Dynamic prediction of correlated color temperature and color rendering index of phosphorcoated white light-emitting diodes," Industrial Electronics, IEEE Transactions on, vol. 61, pp. 784797,2014

P. Manninen and P. Orreveteläinen, "On spectral and thermal behaviors of AlGaInP light-emitting diodes under pulse-width modulation," Applied Physics Letters, vol. 91, p. 181121, 2007.

L. Metrology, "Handbook of LED Metrology,"Instrument Systems GmbH, p. 40, 2000.

D. G. Todorov and L. G. Kapisazov, "LED thermal management," Proceedings of ELECTRONICS, pp. 139-144, 2008.

A. Keppens, W. Ryckaert, G. Deconinck, and P.Hanselaer, "Modeling high power light-emitting diode spectra and their variation with junction temperature,"

Journal of Applied Physics, vol. 108, p. 043104, 2010.

Nasriddinov S.S.Investigation of temperature sensors based on $\mathrm{Si}<\mathrm{P}, \mathrm{Ni}>$.Journal of Nano- and Electronic Physics, 2015, 7(3), 03037. 